\title{
A disciplina interdisciplinar: ambivalências epistemológicas no ensino de Teoria(s) da Comunicação'
}

\section{The interdisciplinary discipline: ambivalences in teaching epistemological theory (s) of Communication}

Luís Mauro Sá Martino I Imsamartino@gmail.com Graduado em Comunicação Social pela Faculdade Cásper Líbero (1998), com Mestrado (2001) e Doutorado (2004) em Ciências Sociais pela Pontifícia Universidade Católica de São Paulo. Foi pesquisador-bolsista na School of Political, Social and International Studies na University of East Anglia, na Inglaterra (2008). Professor da Faculdade Casper Líbero - graduação, pós lato sensu e mestrado. Pertence ao corpo editorial das Revistas Líbero e CoMTempo, da Faculdade Cásper Líbero, e de Comunicação Midiática (Unesp), Comunicação, Mídia e Consumo (ESPM). É também professor no curso de Música da Faculdade Cantareira. Autor dos livros "Mídia e Poder Simbólico"

(Paulus, 2003), "O habitus na Comunicação" (Paulus, 2003), em parceria com Clóvis de Barros Filho, "Comunicação: troca cultural" (Paulus, 2005), "Estética da Comunicação" (Vozes, 2007),

"Teoria da Comunicação" (Vozes, 2009) e "Comunicação e Identidade" (Paulus, 2010). Dentro da Comunicação, suas pesquisas dirigem-se às questões de Teorias da Comunicação, Estudos de Recepção e Identidade, Mídia e Religião, Produção de Notícias e Entretenimento.

\begin{abstract}
Resumo
O que é considerado "teoria" nos estudos de Comunicação? Este texto busca delinear uma resposta a partir dos programas de ensino de "Teoria da Comunicação" de 31 universidades. O exame indica que os debates epistemológicos da área são condensados em um pequeno núcleo de teorias, não havendo consenso a respeito do que constitui uma 'teoria da comunicaçâo'
\end{abstract}

Palavras-Chave: Teoria da Comunicação; epistemologia; ensino.

\begin{abstract}
What has been taught as 'theory' in Communication Studies? This paper outlines an answer by examining the syllabuses of 'communication theory' classes taken from 31 Brazilian universities. Evidence suggests that the richness of epistemological debates are condensed in a core of few 'theories', with a lack of agreement on what is 'theory' in Communication.
\end{abstract}

Keywords: communication theory; epistemology; teaching. 


\section{Introdução}

Qual “teoria da comunicação" está sendo levada para as salas de aula? De que maneira os debates sobre Epistemologia da Comunicação, desenvolvidos em vários espaços (livros, artigos, eventos da área), encontram sua materialidade no discurso teórico da área? A inquietação na origem deste texto é provocada por um problema ao mesmo tempo epistemológico e prático: como decidir o que é uma teoria "da comunicação"? Algum tipo de convicção, ainda que fluida, do que é "comunicação", seus limites teóricos e epistemológicos, precisa ser utilizada.

A prática de sala de aula foi outra motivação deste trabalho, e as questôes propostas são as mesmas que se colocam a cada início de ano ou semestre letivo; não se trata, portanto, de observar o campo de fora, mas de dentro, como participante motivado pelas mesmas questóes. Neste texto, procura-se um diálogo, buscando mais compartilhar dúvidas e comparar caminhos do que oferecer uma resposta.

A sala de aula coloca desafios práticos à Epistemologia da Comunicação no momento em que ela, de certa forma, se objetiva no corpo de conteúdos da disciplina "Teoria da Comunicação". Se os problemas epistemológicos da comunicação ocupam um largo espaço nas discussôes da área, é possível notar menos preocupação com algumas questóes epistemológicas envolvidas no ensino dessa disciplina.

Como lembra Lovisolo (2002, p.2), a decisão a respeito do que deve ou não constar da formação dos participantes de uma área expressa o "grau de acordo, epistemológico e teórico" existente nesse espaço. Como reforça Temer (2007, p.3), “o primeiro passo para uma proposta fundamentada de ensino-aprendizado das Teorias da Comunicação é a compreensão da base epistemológica que determina as diferentes origens destes estudos".

O objetivo deste trabalho é delinear algumas dessas questóes epistemológicas a partir do exame dos programas de ensino de Teoria da Comunicação de trinta e um cursos de graduação do país. Não há aqui a pretensão de uma resposta completa, mas de mostrar algumas das linhas seguidas pelos cursos. A escolha desses programas obedeceu a um critério de abrangência espacial, somado à disponibilidade para consulta. 
Foram estudados os programas das seguintes instituições:

\begin{tabular}{|c|c|}
\hline ECA - USP & UFPR - Universidade Federal do Paraná \\
\hline $\begin{array}{l}\text { FACITEC - Faculdade de Ciências Sociais e } \\
\text { Tecnológicas }\end{array}$ & UFS - Universidade Federal de Sergipe \\
\hline Faculdade Estácio de Sá de Santa Catarina & UFSJ - Universidade Federal de São João del-Rei \\
\hline $\begin{array}{l}\text { FAIMI - União das escolas do grupo FAIMI } \\
\text { - Mirassol }\end{array}$ & UFSM - Universidade Federal de Santa Maria \\
\hline FDJ - Faculdade 2 de Julho & UFU - Universidade Federal de Uberlândia \\
\hline FIB - Centro Universitário da Bahia & UNAERP - Universidade de Ribeirão Preto \\
\hline UCG - Universidade Católica de Goiás & UnB - Universidade de Brasília \\
\hline UCS - Universidade de Caxias do Sul & UnC - Universidade do Contestado \\
\hline $\begin{array}{l}\text { UERJ - Universidade do Estado do Rio de } \\
\text { Janeiro }\end{array}$ & $\begin{array}{l}\text { UNEF - Unidade de Ensino Superior de Feira } \\
\text { de Santana }\end{array}$ \\
\hline UFBA - Universidade Federal da Bahia & $\begin{array}{l}\text { UNICAMP }- \text { Universidade Estadual de } \\
\text { Campinas }\end{array}$ \\
\hline UFC - Universidade Federal do Ceará & UNIDERP - Universidade Anhanguera \\
\hline UFG - Universidade Federal de Goiás & UNIFAE - Faculdades Associadas de Ensino \\
\hline UFMG - Universidade Federal de Minas Gerais & UNIFOR - Universidade de Fortaleza \\
\hline UFPA - Universidade Federal do Pará & UNIFRA - Centro Universitário Franciscano \\
\hline UFPE - Universidade Federal de Pernambuco & UTP - Universidade Tuiuti do Paraná \\
\hline
\end{tabular}

Foram comparadas as ementas, os ítens dos conteúdos programáticos e as bibliografias, geral e específica, para delinear, a partir da coincidência/ divergência entre os temas, os saberes ensinados sob o nome "Teoria da Comunicação". O objetivo não é avaliar a qualidade dos programas ou legislar sobre o que deve ser ensinado, mas observar os elementos ensinados e pensar nas questóes epistemológicas subjacentes a essas escolhas.

Vale lembrar que náo se pode tomar o que é explicitado nos programas como um retrato do que é efetivamente ensinado em sala de aula. A presença de uma autora na bibliografia, por exemplo, não permite inferir qual é o tratamento dado a ela pelo professor em sala de aula. Os programas de ensino, aqui, são tomados como indicaçóes a partir das quais se pode delinear questóes epistemológicas, não como um mapa ou retrato da prática em sala de aula.

\section{O lugar da disciplina nos cursos de Comunicação}

Matéria presente nos cursos de Comunicação desde a regulamentação dos cursos, Teoria da Comunicação apresenta-se como uma disciplina de fronteiras móveis, na qual saberes de várias áreas são agrupados em torno de objetos e temas nem sempre consensuais. O que é "Teoria da Comunicação" em uma universidade pode não ser em outra, e é possível dizer que essa indefinição de alguma maneira talvez esteja ligada aos problemas epistemológicos da área desde sua consolidação como ensino superior (MARTINO, 2009). Seria possível encontrar uma ressonância desses problemas no conteúdo dos programas examinados - por exemplo, a questáo do objeto de estudos e da interdisciplinaridade (BARBOSA, 2002). 
O campo da comunicação parece ser suficientemente elástico para compreender uma gama de objetos nos quais o caráter especificamente "comunicacional" pode ser detectado com mais ou menos facilidade. Vale perguntar também, de saída, o quanto a detecção desse caráter "comunicacional" não está ligada à concepção que se tem das implicações metodológicas da "comunicação".

Se a experiência empírica da sala de aula pode ser um parâmetro, vale lembrar que uma das consequências é a percepção, pelos estudantes, de que determinados saberes efetivamente se constituem como sendo "a" ou "as" teoria(s) da Comunicação. Sem dispor necessariamente de um repertório conceitual para questionar se aqueles saberes são, de fato, "Teoria da comunicaçáo", alunos de graduação podem intuir a questão a respeito das fronteiras disciplinares, mas nem sempre terão como formular uma dúvida epistemológica sobre a apresentação dos conteúdos x ou y sob esse nome.

Seria o caso de lembrar que os cursos de Comunicação referem-se, de fato, a habilitaçóes dentro de um corpo de saberes técnicos - Jornalismo, Publicidade \& Propaganda, Relações Públicas, Rádio \& TV, Editoração, etc. Essa característica se relaciona com um problema apontado por Venício Lima (1983) décadas atrás sobre uma "crise de identidade" dos cursos de Comunicação ainda presente. Trata-se de uma dicotomia que, de alguma forma, reflete a estruturaçáo do curso em torno de demandas de mercado oscilando entre um saber humanístico e um saber técnico que divide os cursos em troncos de disciplinas teóricas e práticas.

Há ainda um outro aspecto no que diz respeito às relaçóes entre Epistemologia da Comunicação e o ensino de Teorias da Comunicaçáo. A busca pelas práticas de ensino ou pela constituição dos currículos dentro dos cursos de Comunicaçáo certamente pode ser visto como um problema ligado, a princípio, às discussóes de uma Pedagogia da Comunicação. No entanto, o que se procura aqui é construir relaçóes entre os debates epistemológicos que vem, há pelo menos duas décadas, verificar quais são os principais problemas referentes aos objetos, métodos e teorias da área e o momento em que esses debates efetivamente devem encontrar sua materialidade discursiva na forma de programas de disciplinas, nos quais as escolhas a respeito do que chegará ou não a fazer parte do diálogo com alunos e pesquisadores se pautam em critérios que, a princípio, remetem a uma investigação epistemológica sobre o que constitui os fundamentos da área.

A escolha pela disciplina "Teoria(s) da Comunicação" se deve ao fato de que, embora existam outras "matérias teóricas" nos cursos de graduação, é possível esperar que esse seja um dos espaços privilegiados para a discussão dos conceitos, métodos e objetos que efetivamente constituirão a área.

A disciplina "Teoria da Comunicação" está, ao lado de outras que não deixam de ser estudos teóricos da Comunicação, aumentando a possibilidade de confusão a respeito da especificidade dessa disciplina. A formação de um corpo doutrinário significa o estabelecimento, mais ou menos consensual, das falas legítimas, dos autores que seráo acatados como passíveis de discussão, bem como os que, por diversos motivos, serão apartados de qualquer tipo de referência. 
Nesse caso, a pergunta deste texto poderia ser resumida em uma frase: qual é o discurso epistemológico de "Teoria da Comunicaçáo", tal como definida por sua prática em sala de aula nos cursos de graduação? A resposta será delineada, em primeiro lugar, pela observação das ementas e tópicos referentes aos conteúdos e, na sequência, com o exame da bibliografia.

\section{Entre o cânone mínimo e a dispersão teórica: tópicos dos pro- gramas de ensino}

A maior parte dos programas estudados aborda o tema a partir de "escolas teóricas" ou de referências teóricas específicas - por exemplo, entre "Cultura de Massa” e "Escola de Frankfurt" ou pesquisas sobre técnica/ tecnologia e McLuhan. A discussão propriamente epistemológica a respeito da comunicaçáo parece estar ausente da maior parte deles - apenas 13 dos 31 programas dedicam algum espaço ao tema. O enfoque por teorias ou escolas, predominante, reserva pouco espaço às discussóes sobre objeto, teoria e métodos da comunicação. $\mathrm{O}$ assunto está confinado ao início ou ao final dos cursos, restrito a um ponto ou dois do programa.

É o caso de questionar se o aluno em um primeiro semestre de graduação estaria pronto para o mergulho em questóes mais complexas, objeto de dissenso mesmo entre os pesquisadores da área. No entanto, talvez essa discussão pudesse servir de partida para explicar as diferentes concepçóes de comunicação apresentadas e trabalhadas pelas diversas escolas ou métodos.

Um limite da análise dos programas refere-se à impossibilidade de saber, efetivamente, quais são as discussões epistemológicas agrupadas sob essas rubricas. No entanto, é possivel mencionar uma preocupação, em primeiro lugar, com o objeto (UnC, Uniderp, UCG e UFG) e com as relaçóes entre Comunicação e outras ciências sociais (UFS, Unifra, UFSJ, UFPA, UFG, UCG).

A UFPA e a Universidade Católica de Goiás contemplam uma variada gama de questóes epistemológicas referentes à interdisciplinaridade, objeto e método da comunicação. Vale notar também, como caso isolado, uma preocupação da UFC em discutir a diferença entre "Teorias da Comunicação" e "Teorias da Comunicação de Massa” como tópicos do programa.

\section{Escolas e teorias da comunicação}

Dentre os programas que optam por uma divisão por teorias ou escolas, nota-se uma predominância das teorias da comunicaçáo desenvolvidas em meados do século XX. Seria possível falar mesmo em um "cânone mínimo" ou um "núcleo temático" de temas oriundos de fontes epistemológicas diversas.

Esses saberes seriam representados pelos temas com maior número de mençóes entre os programas observados - a pesquisa norte-americana em comunicação, em suas várias denominações (mass communication research, escola norte-americana, funcionalismo), seguido da Escola de Frankfurt, mencionada 
também como "Indústria Cultural” ou "Teoria Crítica”, e a obra de Marshall McLuhan. Pode-se notar, assim, o predomínio quantitativo de teorias criadas há mais de cinqüenta anos.

Se existe um cânone na teoria da comunicação ensinada, ele é constituído por um duplo eixo formado pela Escola de Frankfurt, Estudos Norte-Americanos e McLuhan, aos quais se juntam de maneira tímida os Estudos Culturais. Apenas esses quatro tópicos, de um total de 101 possíveis, são encontrados em mais da metade dos programas analisados - um total de 2,43\%. Do total de 101 tópicos incluídos nos 31 programas, onze estão presentes em mais de um.

A tabela permite dimensionar o fato:

Tabela 01: Número de citaçóes de autores e escolas em programas de ensino

\begin{tabular}{|l|l|}
\hline Autor / Escola & Citaçóes \\
\hline Escola de Frankfurt & 23 \\
\hline Escolas Norte-Americanas & 20 \\
\hline Estudos Culturais & 13 \\
\hline Questôes Epistemológicas & 13 \\
\hline McLuhan & 12 \\
\hline Estruturalismo / Semiótica & 12 \\
\hline Escolas Latino-Americanas & 9 \\
\hline Cibercultura / Redes & 4 \\
\hline Newsmaking e Pesquisa de Efeitos & 2 \\
\hline Umberto Eco & 2 \\
\hline
\end{tabular}

À primeira vista, a composição dos programas pode parecer muito semelhante, sobretudo no que diz respeito aos cinco eixos identificados Escola de Frankfurt, Funcionalismo Norte-Americano, Estudos Culturais, Estruturalismo e Marshall McLuhan.

O desafio epistemológico, no entanto, não parece residir no consenso, mas na dissonância entre os outros tópicos. A quantidade de tópicos presentes em um único programa aponta para a falta de consenso entre os tópicos e conteúdos dos programas. O grau de coincidência a respeito do que é Teoria da Comunicação é de apenas $10.89 \%$, deixando um espaço de $89.11 \%$ de diversidade.

Nota-se, espalhadas pelos programas, duas perspectivas divergentes a respeito do objeto da comunicação. De um lado, o foco nos meios de comunicação; de outro, uma visão que compreende a comunicação como processo social interacional. Essa dicotomia, como explica Felinto (2007, p.43), reflete uma discussão presente nos debates epistemológicos, a respeito da constituição de um objeto da Comunicação, pensado como estudo da comunicação em sua intersecção com as mídias, em particular as chamadas "mídias de massa” e as mídias eletrônicas, ou como o estudo das relaçóes e interaçóes entre seres humanos. 
Os programas analisados parecem combinar essas duas perspectivas quando pensados em sua totalidade. Boa parte deles, apresentando uma perspectiva que pode ser chamada de "panorâmica", desenvolve um discurso em váris direçôes. Essa diversidade nos tópicos das ementas é acompanhada de perto pela dispersão que pode ser encontrada nas bibliografias, como será visto no próximo ítem.

\section{Uma disciplina ou várias? Dispersão disciplinar e elasticidade do campo}

A presença de um cânone mínimo e da dispersão epistemológica também pode ser observada na bibliografia. Os programas de ensino mencionam um total de 224 autores, dos quais pouco mais da metade, 135, ganha uma única citação. Nota-se, nos autores presentes em mais de cinco programas de ensino, uma predominância dos livros-textos.

Tabela 02: Distribuição de autores presentes em mais de cinco programas

\begin{tabular}{|l|l|l|}
\hline Em mais de 10 programas & Sete a nove programas & Cinco e seis programas \\
\hline & & \\
\hline Mauro Wolf (21) & Lucien Sfez (09) & Adriano Duarte Rodrigues (6) \\
\hline Armand Mattelart (20) & Francisco Rüdiger (9) & Pierre Levy (6) \\
\hline Umberto Eco (19) & Jesus Martin-Barbero (9) & Teixeira Coelho (6) \\
\hline Lúcia Santaella (16) & Gabriel Cohn (9) & Daniel Bougnoux (6) \\
\hline Luiz Costa Lima (15) & John B. Thompson (8) & Jean Baudrillard (6) \\
\hline Antonio Hohfeldt et alli (13) & Ciro Marcondes Filho (8) & Paul Watzlawick (5) \\
\hline Marshall McLuhan (12) & Roland Barthes (8) & Eliseo Verón (5) \\
\hline $\begin{array}{l}\text { Melvin DeFleur \& Sandra } \\
\text { Ball-Rokeach (12) }\end{array}$ & $\begin{array}{l}\text { Theodor Adorno \& Max } \\
\text { Horkheimer (7) }\end{array}$ & $\begin{array}{l}\text { Ilana Politschuk \& Aluízio } \\
\text { Trinta (5) }\end{array}$ \\
\hline & Pedro Gilberto Gomes (7) & Juan Diaz Bordenave (5) \\
\hline & José Marques de Melo (7) & Luiz Beltrão (5) \\
\hline & David K. Berlo (7) & \\
\hline & Edgar Morin (7) & \\
\hline
\end{tabular}

Os autores mais citados, Mauro Wolf e Armand \& Michelle Mattelart, não estão presentes com estudos originais de Comunicação, mas por seus livros-texto. O mesmo poderia ser dito a respeito do livro de Luiz Costa Lima, Teoria da Cultura de Massa, presente em 15 programas, ou de Comunicação e Indústria Cultural, de Gabriel Cohn, em nove. Embora seja a escola teórica mais presente nos programas, os autores da Escola de Frankfurt não estão entre os mais citados: Adorno e Horkheimer aparecem diretamente em apenas sete programas. Não há nem um único autor que seja considerado como apto a figurar na bibliografia de "Teoria da Comunicação" em todos os programas. 
Em primeiro lugar, verifica-se uma concentração de autores efetivamente empenhados no desenvolvimento de reflexôes sobre a comunicação humana em seus vários aspectos, mas guardando uma perspectiva da centralidade dos processos de comunicação, mediados eletronicamente ou não.

Identifica-se que há uma espécie de formação do desenho do campo, ao menos no que se torna visível pela interpretação da bibliografia: os livros mais citados em Teoria da Comunicação parecem se dividir em (a) livros sobre os meios de comunicação e suas relações com as dimensões sociais, políticas e psicológicas do humano; (b) livros sobre o humano explicado a partir de sua perspectiva comunicacional; (c) uma abordagem das interaçóes humanas, mediada eletronicamente ou não, explicadas como processos semióticos de comunicação. Parece persistir, assim, uma certa dualidade, apontada por vários autores (FERREIRA, 2003; BRAGA, 2004; 2010; MARTINO, 2005; MARTINO, 2009), a respeito do que é o objeto da comunicação, se são os meios de comunicação ou as interações humanas.

Analisando o conjunto de autores citados em mais de um programa, é possível ter uma dimensão da elasticidade epistemológica do campo da Comunicação. A origem doutrinaria dos autores ainda aponta para a predominância de ligaçóes com outras áreas das humanidades, e é a partir daí que se pode observar em contornos talvez um pouco mais nítidos a "elasticidade" mencionada.

De um lado, nota-se a predominância das temáticas que contemplam, em algum momento, a centralidade dos meios de comunicação ou de aspectos culturais ligados a eles - seria o caso, por exemplo, das obras de Morin, Baudrillard ou Maffesolli que, em algum momento, discutem mídia. No entanto, talvez não esteja claro na mesma medida, por exemplo, a presença de autores como Geertz ou Hjelmslev: não se estaria aí no limite da Antropologia ou da Linguística? Se essas abordagens, temáticas e objetos constituem elemento de discussão em "Teoria da Comunicação", quais seriam os critérios epistemológicos para definir os contornos da disciplina e da área?

Conforme se avança na observação dos autores citados, a aparente organização dos programas em torno dos eixos mencionados vai se tornando mais difusa, sugerindo com mais força a ausência de contornos nítidos do campo. Quando se passa à observação dos autores e obras citados por um único programa é possível perceber a quantidade de domínios, áreas e temas sancionados pela rubrica "Teoria da Comunicação". Seria o caso de compreender a presença dessas obras como um recurso interdisciplinar ou como um indício de fraqueza epistemológica do campo?

De certo modo, a transformação de uma área do saber em uma disciplina específica é uma maneira de aglutinar poderes e forças em torno de um grupo de discussões comuns. Se não se deve talvez exagerar nessa perspectiva, vale recordar que a atribuição de sentidos, bem como a construção de disciplinas e áreas do saber, não se dá de maneira fortuita: 
Há, pois, uma extensão enorme de fenômenos associados à palavra comunicação. Isso, se por um lado, tem como aspecto positivo desqualificar a idéia de disciplinaridade, por outro lado cria uma dependência de outros saberes, o que foi historicamente um dos maiores entraves à própria autonomização do campo (BARBOSA, 2002, p.74).

Essa pluralidade, bem como a mencionada "dependência", parece se manifestar com especial propriedade quando se observa o amplo panorama delineado pelos programas de Teoria da Comunicação, de maneira a constituir um espaço próprio para a verificação de certa dispersão epistemológica da área.

Mais ainda, seriam essas teorias específicas "teorias da comunicação"? Seria o caso de pensar na advertência de Luiz C. Martino (2005) a respeito do tema, quando afirma que, "acompanhando esta tendência interdisciplinar, as teorias da comunicação, deveriam abarcar e talvez coincidir com o conjunto das teorias das ciências do homem, ou qualquer coisa próxima disso"? Isso implica reservar um espaço para pensar a questão interdisciplinar na construção dos currículos de Teoria da Comunicação.

A apresentação do campo da comunicação como "interdisciplinar" parece ser quase um consenso entre as pesquisas na área. Torna-se, portanto, necessário entender um pouco melhor essa definiçáo presente em várias discussóes sobre a validade teórica e os limites epistemológicos da Comunicaçáo.

O estudo dos programas sugere que a maior parte dos trabalhos clássicos usados como "teoria da comunicação" foram escritos por pessoas oriundas de outros campos. A produção de textos sobre comunicação é subsidiária de métodos, teorias e conceitos de outros campos de conhecimento, sobretudo das ciências sociais. Em um estudo sobre os últimos cinqüenta anos de pesquisa em Comunicação nos Estados Unidos, Bryant e Miron (2004:665) constatam, com ampla base empírica, que "uma considerável porção das teorias da comunicação utilizadas na pesquisa são derivadas da psicologia e da sociologia, com importantes contribuiçóes do direito e da política”.

É possível argumentar, de saída, que essa articulação múltipla de saberes em Teoria da Comunicação de alguma maneira reflete as condiçóes interdisciplinares da própria área de Comunicação, conforme apontada por vários autores (Barbosa, 2002). Se a Comunicação pode ser definida como uma área de cruzamento de saberes em torno de um grupo de objetos, é talvez coerente que a disciplina na qual essas discussóes são o ponto central também de alguma maneira reproduza essa interdisciplinaridade.

Se é possível pensar a existência de uma ciência também como espaço discursivo, a formação de um corpo doutrinário significa o estabelecimento, mais ou menos consensual, das falas legítimas dentro dele, dos autores que serão acatados como passíveis de discussão - as "linhagens" e "percursos" da área da comunicação (MARTINO, 2005; FERREIRA, 2007).

A hegemonia de teorias, escolas e autores estrangeiros é clara. Pode ser justificada do ponto de vista da própria história da Teoria da Comunicação, vinda da Europa e dos Estados Unidos por conta do desenvolvimento em larga escala dos meios de comunicação de massa, uma das fontes do moderno pensamento sobre o tema. 
Essa disparidade entre o que é ou deixa de ser pertencente à "teoria da comunicação", seja como disciplina, seja como campo do conhecimento, área do saber ou qual outro nome se utilize é a parte mais externa do problema. Trata-se de encontrar um estatuto epistemológico a partir do qual seria possível identificar o princípio de uma teoria da comunicação.

\section{Interrogações Finais}

O que é, de fato, uma teoria da comunicação? A julgar pela pluralidade de autores, escolas, conceitos e teorias incluídos nos programas, há uma séria indefinição a respeito das fronteiras entre o que é um estudo de comunicação. Nota-se a aplicação de teorias sociológicas, psicológicas, antropológicas, filosóficas e mesmo matemáticas ao estudo da comunicação. Haveria, nesse caso, uma teoria da comunicação ou teorias aplicadas à comunicação?

Essa discussão parece ser o elo entre o ensino de Teoria da Comunicação e as questôes epistemológicas da área. Nesse caso, a pertinência ou não de uma escola ou teoria estaria ligada diretamente ao que se entende por "comunicação", bem como à maneira pela qual essas decisóes efetivamente se materializam no discurso disciplinar de "Teoria da Comunicação" como um espaço particularmente apto, embora certamente não o único, para indicar algumas questôes relativas aos problemas epistemológicos da área.

A dimensão acadêmica de um campo do conhecimento objetiva-se, entre outras coisas, na produçáo de um corpo doutrinário próprio, decorrente das pesquisas específicas na área. É preciso lembrar que:

as teorias das áreas vizinhas, mesmo quando tratam diretamente de comunicação, o fazem com atribuição de maior relevância a questôes habituais da área própria, perante as quais os fenômenos comunicacionais sáo coadjuvantes - o que não ajuda no esforço de desentranhamento do "objeto comunicacional" e das questóes pertinentes para o campo (BRAGA, 2007, p.26).

Dessa maneira, quanto maior a auto-referência doutrinária, maior o grau de autonomia relativa de um campo, argumenta Lovisolo (2002). Como ficaria, então, a situação paradoxal do campo da comunicação, que se apresenta como um campo interdisciplinar. Aos olhos de um critico apressado, esse tipo de definição mostraria uma contradição nos termos, a saber, a enunciação da falência do campo ocorre em sua própria definição.

É possível notar, no exame dos programas de ensino e das bibliografias, a existência de uma espécie de "núcleo" principal, formado pelas teorias mais antigas, ao lado de uma considerável dispersão teórica e conceitual observável na medida em que, a julgar pela disparidade encontrada, virtualmente qualquer aglomerado de ideias pode ser incluíndo dentro dos estudos de Comunicação.

A construção de interfaces entre a Comunicação e outras áreas do saber parece ainda reforçar essa posição, fazendo com que em alguns momentos seja necessário algum esforço no sentido de verificar a efetiva pertinência de uma teoria à área de Comunicação. A presença de temas das chamadas "áreas afins" parece ser uma das características principais, o que pode, por outro lado, ser 
lido também como um indício de certa fragilidade do campo no que diz respeito à constituição de um cânone teórico-metodológico.

Certamente é possível questionar, de saída, a necessidade disso: até que ponto a dispersão epistemológica não é, por si só, uma das características de riqueza da área? A pluralidade de objetos, métodos e conceitos implica também uma abertura que talvez não seja característica de todas as áreas do saber e, ao mesmo tempo, oferece um leque de opçóes ao pesquisador para a investigação de objetos que não necessariamente encontrariam seu espaço em outras áreas.

Observaçóes pontuais auxiliam a pensar esta questão:

Nota-se a presença de uma espécie de um cânone mínimo englobando cerca de dez "teorias" ou "escolas teóricas", assim como dez obras de referência. Para além desse limite, o índice de dispersão é considerável, mostrando um dissenso sobre o que pode ser incluído em "teoria da comunicação", algo observado em pesquisas anteriores (PERUZZO, 2002; MARTINO, 2008; 2009). O baixo grau de coincidência sugere ao mesmo tempo uma área de abrangência muito grande e a inexistência de limites claros, o que remete à terceira consideração.

Em termos do que seria uma "grande teoria", o campo não parece ter incorporado ao ensino nada posterior a 1987, com a publicaçáo de De los medios a las mediaciones, marco inicial da "Teoria das Mediaçóes". A exceção é o grupo de títulos e autores sobre Internet em suas modalidades - cultura de rede, cibercultura, redes virtuais, etc.

Cabe observar a apropriação e permanência da "Escola de Frankfurt" pelo discurso da Teoria da Comunicação, fato constatado em pesquisas diversas nos últimos anos.

Um último aspecto leva em conta a formação docente: a amplitude do espectro de teorias apresentadas nos programas parece exigir de quem leciona Teoria da Comunicação um repertório apto a transitar por diversas áreas do saber, atravessando espaços da Filosofia, Ciências Sociais, Política e Letras, para não mencionar a Semiótica, o necessário conhecimento de História e mesmo de Lógica Matemática necessários para dar conta dos pontos do programa.

Gostaria de terminar retomando a pergunta do início: qual teoria da comunicação está sendo levada para as salas de aula? A pesquisa dos 31 programas de ensino sugere que existe um "núcleo central" constituído de cinco ou seis teorias, cercado por um oceano de diversidade. O desafio, para docentes, pesquisadores e, por que não, alunos, está na articulação desses conteúdos com a experiência cotidiana, transformada em uma prática significativa nos estudos de comunicação.

\section{Referências Bibliográficas}

BARBOSA, M. Paradigmas de construção do campo comunicacional. In. Hohfeld, A. et alli. Tensóes e Objetos da Pesquisa em Comunicação. Porto Alegre, Sulina, 2002. 
BRAGA, J. L. Comunicação, disciplina indiciária. Trabalho apresentado ao GT Epistemologia da Comunicação, do XVI Encontro da Compós, na UTP, em Curitiba, PR, em junho de 2007.

BRYANT, J. e MIRON, D. Theory and Research in Mass Communication. Journal of Communication. December 2004/Vol. 54 no. 4, p.665.

FELINTO, E. Patologias no sistema da comunicação: ou o que fazer quando seu objeto desaparece. In: FERREIRA, G. e MARTINO, L. C. Teorias da Comunicação. Salvador: Ed. UFBA, 2007.

FERREIRA, J. Questōes e linhagens na construção do campo epistemológico da comunicação. In: FERREIRA, J. et alli. Cenários, teorias e epistemologias da comunicação. Rio de Janeiro: E-Papers, 2007.

LIMA, V. Repensando as teorias da comunicação. In: MELO, J. M. Teoria e pesquisa em comunicação. São Paulo: Intercom/Cortez, 1983, p. 86.

LOVISOlO, H. Epistemologia prática do campo da Comunicação. Trabalho apresentado ao GT Epistemologia da Comunicação, do XII Encontro da Compós, UFRJ, Rio de Janeiro: em junho de 2002.

MARTINO, L. C. Apontamentos epistemológicos sobre a fundação e a fundamentação do campo comunicacional. In: CAPPARELLI, S. et alli. $A$ Comunicação Revisitada. Porto Alegre: Sulina, 2005.

MARTinO, L. M. Teoria da Comunicaçâo. Petrópolis: Vozes, 2009.

TEMER, A. C. Teorizar é pensar a prática: uma reflexão sobre o ensino das Teorias da Comunicaçáo nos Cursos de Jornalismo. Texto apresentado no $10^{\circ}$ Encontro Nacional de Professores de Jornalismo - Goiânia-GO -27 a 30 de abril de 2007.

\section{Notas}

1. Uma versão preliminar deste texto foi apresentado no DT 8 - Estudos Interdisciplinares do XVI Congresso de Ciências da Comunicação na Região Sudeste realizado de 12 a 14 de maio de 2011. O autor agradece os comentários e sugestốes dos colegas. 